\title{
SMAC mimetic Debio 1143 synergizes with taxanes, topoisomerase inhibitors and bromodomain inhibitors to impede growth of lung adenocarcinoma cells
}

\author{
Casey G. Langdon ${ }^{1, *}$, Norbert Wiedemann ${ }^{2, *}$, Matthew A. Held ${ }^{1,6}$, Ramanaiah \\ Mamillapalli ${ }^{1}$, Pinar Iyidogan ${ }^{1}$, Nicholas Theodosakis ${ }^{1}$, James T. Platt ${ }^{1,3}$, Frederic \\ Levy $^{2}$, Gregoire Vuagniaux ${ }^{2}$, Shaomeng Wang ${ }^{5}$, Marcus W. Bosenberg ${ }^{1,4}$ and David \\ F. Stern ${ }^{1}$ \\ ${ }^{1}$ Department of Pathology and Yale Cancer Center, Yale University School of Medicine, New Haven, CT, USA \\ 2 Debiopharm International SA, Lausanne, Switzerland \\ ${ }^{3}$ Breast Medical Oncology Group, Yale Cancer Center, New Haven, CT, USA \\ ${ }^{4}$ Departments of Dermatology and Yale Cancer Center, Yale University School of Medicine, New Haven, CT, USA \\ ${ }^{5}$ Comprehensive Cancer Center, University of Michigan, Ann Arbor, MI, USA \\ ${ }^{6}$ Massachusetts General Hospital Cancer Center, Harvard Medical School, Charlestown, MA, USA \\ * These authors have contributed equally to this work \\ Correspondence to: David F. Stern, email: df.stern@yale.edu
}

Keywords: SMAC mimetic, combination therapy, lung adenocarcinoma, high throughput screening, bromodomain inhibitor Received: September 25,2015 Accepted: September 26, $2015 \quad$ Published: October 16, 2015

This is an open-access article distributed under the terms of the Creative Commons Attribution License, which permits unrestricted use, distribution, and reproduction in any medium, provided the original author and source are credited.

ABSTRACT

Targeting anti-apoptotic proteins can sensitize tumor cells to conventional chemotherapies or other targeted agents. Antagonizing the Inhibitor of Apoptosis Proteins (IAPs) with mimetics of the pro-apoptotic protein SMAC is one such approach. We used sensitization compound screening to uncover possible agents with the potential to further sensitize lung adenocarcinoma cells to the SMAC mimetic Debio 1143. Several compounds in combination with Debio 1143, including taxanes, topoisomerase inhibitors, and bromodomain inhibitors, super-additively inhibited growth and clonogenicity of lung adenocarcinoma cells. Co-treatment with Debio 1143 and the bromodomain inhibitor JQ1 suppresses the expression of C-IAP1, C-IAP2, and XIAP. Non-canonical NF-KB signaling is also activated following Debio 1143 treatment, and Debio 1143 induces the formation of the ripoptosome in Debio 1143-sensitive cell lines. Sensitivity to Debio 1143 and JQ1 co-treatment was associated with baseline caspase-8 expression. In vivo treatment of lung adenocarcinoma xenografts with Debio 1143 in combination with JQ1 or docetaxel reduced tumor volume more than either single agent alone. As Debio 1143-containing combinations effectively inhibited both in vitro and in vivo growth of lung adenocarcinoma cells, these data provide a rationale for Debio 1143 combinations currently being evaluated in ongoing clinical trials and suggest potential utility of other combinations identified here.

\section{INTRODUCTION}

The ability of tumor cells to evade apoptosis is crucial for tumor biology. The inhibitor of apoptosis proteins (IAPs) are important mediators of the antiapoptotic phenotype. IAPs are highly expressed in most tumors [1]. All eight IAP family members have at least one BIR (baculovirus IAP repeat) domain that interacts with and inhibits the catalytic activity of caspases [2]. Three IAP family members - cIAP1, cIAP2, and XIAP - also have RING (really interesting new gene) domains with E3 ubiquitin ligase activity [2]. These three IAPs modulate ubiquitin-mediated proteasomal degradation of proteins and ubiquitin-mediated signaling events [2]. 
Table 1: $\mathrm{GI}_{50}, \mathrm{GI}_{25}$, and $\mathrm{GI}_{10}$ values for Debio 1143 in the panel of lung adenocarcinoma cell lines used for sensitization screening

\begin{tabular}{|l|l|c|c|c|}
\hline \multirow{2}{*}{ Cell Line } & \multicolumn{1}{|c|}{ Mutation Status } & \multicolumn{3}{c|}{ Debio1143 } \\
\cline { 3 - 5 } & & Gl50 & Gl25 & G/10 \\
\hline \hline A549 & KRAS (G12S), STK11, SMARCA4, CDKN2A & $100^{*}$ & 50.35 & 18.02 \\
\hline H2030 & KRAS (G12C), STK11, SMARCA4, TP53 & 65.39 & 27.25 & 7.15 \\
\hline H1650 & EGFR (746-750del), TP53, CDKN2A, PTEN del & $100^{*}$ & 73.23 & 14.94 \\
\hline H1975 & EGFR (L858R, T790M), TP53, CDKN2A, PI3KCA & 21.30 & 2.29 & 0.28 \\
\hline H820 & EGFR (746-750del, T790M), MET amp & 2.55 & 0.65 & 0.25 \\
\hline H2228 & EML4-ALK variant 3, CDKN2A, RB1, TP53 & 38.87 & 5.36 & 0.40 \\
\hline
\end{tabular}

${ }^{*} \mathrm{GI50}$ never achieved. Highest concentration used in screening experiments

IAP-mediated non-degradative ubiquitination of RIP1 leads to activation of the inhibitor of NF- $\kappa$ B kinase (IKK), phosphorylation and proteasomal degradation of $\mathrm{I} \kappa \mathrm{B} \alpha$, and nuclear localization of the transcriptional effector subunits of NF- $\kappa B$ [2-4]. IAP-mediated ubiquitination of NIK (NF$\kappa \mathrm{B}$-inducing kinase) inactivates the non-canonical NF- $\kappa \mathrm{B}$ pathway $[2,5,6]$.

Second mitochondrial-derived activator of caspases (SMAC) is an endogenous inhibitor of IAPs [7]. Stimulation of apoptotic pathways releases SMAC from mitochondria; the amino-terminus of SMAC is then proteolytically cleaved, exposing a four amino acid motif that binds to BIR domains in XIAP, cIAP1, and cIAP-2. This prevents IAPs from binding caspases [7-10]. SMAC also promotes the auto-ubiquitination and subsequent degradation of cIAP1 and cIAP2, but not XIAP [7, 11].

Small molecule SMAC mimetics are in various stages of clinical development. They function similarly to endogenous SMAC by antagonizing the inhibition of caspases mediated by XIAP and by inducing the auto-ubiquitination of cIAP1 or cIAP2; subsequent NF$\kappa \mathrm{B}$-induced expression of $\mathrm{TNF} \alpha$ further activates proapoptotic TNFR1 (TNF $\alpha$ receptor) signaling [12-14]. Downregulation of the anti-apoptotic protein c-FLIP is necessary for sensitivity of breast cancer cell lines to SMAC mimetics [15]. SMAC mimetic-induced loss of IAP function is also associated with formation of the cell-death inducing complex - the ripoptosome $[16,17]$. However, ripoptosome formation does not require $\mathrm{TNF} \alpha$ expression. The ripoptosome mediates both caspase-8dependent apoptosis and caspase-independent necroptosis [16].

Only a subset of non-small cell lung cancer cell lines responds to SMAC mimetics as single agents, supporting the need for combination therapy treatment [14]. SMAC mimetics synergize with conventional chemotherapeutics including paclitaxel, gemcitabine, cisplatin, carboplatin [18] and the topoisomerase inhibitor SN-38 in a variety of tumors (reviewed in [2]). SMAC mimetics also sensitize tumor cells to radiation therapy $[19,20]$. Here, we describe a sensitization screen using the SMAC mimetic Debio 1143 (AT-406) to identify effective partner agents for the treatment of lung adenocarcinoma cells with various driver and resistance mutations. Debio 1143 is an orally available IAP inhibitor being developed in combination with chemo and radiotherapy in various solid tumors (ClinicalTrials. gov Identifier: NCT01930292) [21]. The combination screen revealed novel combinations with Debio 1143 that induce apoptosis, intercellular signaling alterations, and xenograft efficacy.

\section{RESULTS}

\section{Lung adenocarcinoma cell lines are differentially responsive to Debio 1143}

Six lung adenocarcinoma cell lines, with $K R A S$, $E G F R$, or $A L K$ driver mutations were evaluated for Debio 1143 dose-dependent growth inhibition to identify optimal concentrations for use in combination assays (Table 1). The two most sensitive cell lines, H1975 and H820, have EGFR driver mutations and are resistant to erlotinib as they harbor gatekeeper T790M mutations. The T790M substitution does not affect sensitivity to Debio 1143, as matched pairs of erlotinib-sensitive parental and derivative erlotinib-resistant (T790M) cell lines have similar Debio 1143 dose response profiles (Figure S1A). Two of the other four lines tested - H2030 (KRAS mutation) and H2228 (EML4-ALK translocation) - were less sensitive to Debio 1143. A549 and H1650 cells were resistant (Table 1). Hence, subsets of lung adenocarcinoma lines with three different common driver mutations are sensitive to Debio 1143 .

\section{Debio 1143 combination screen}

We sought to identify partner agents that would augment efficacy and potency of Debio 1143, using a sensitization combination screening format illustrated in Figure 1. The six cell lines described in Table 1 were screened against 128 agents (Table S1). These compounds inhibit a range of different target classes including components of growth factor signaling pathways, 


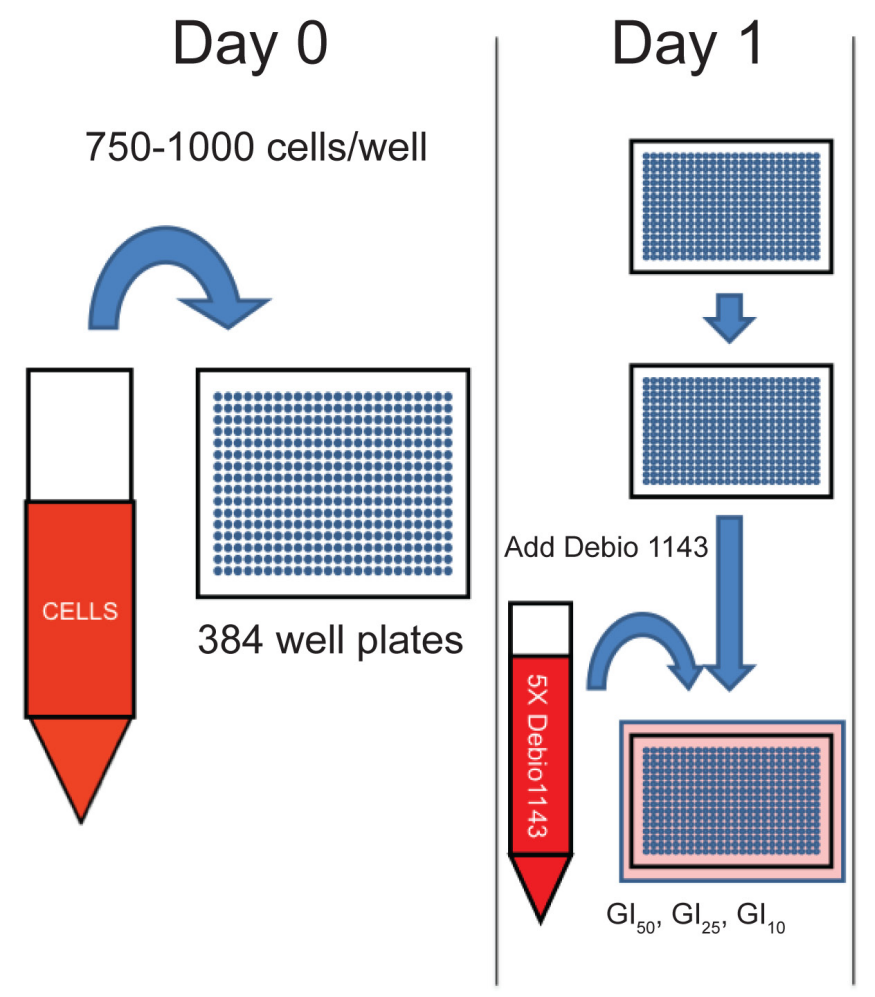

\section{Day 4}
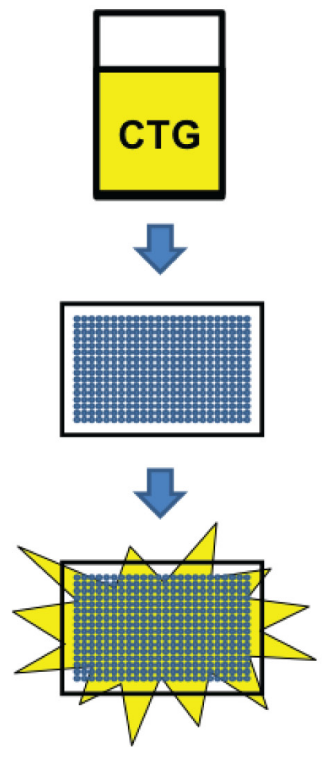

Figure 1: Schematic of Debio 1143 sensitization screen.

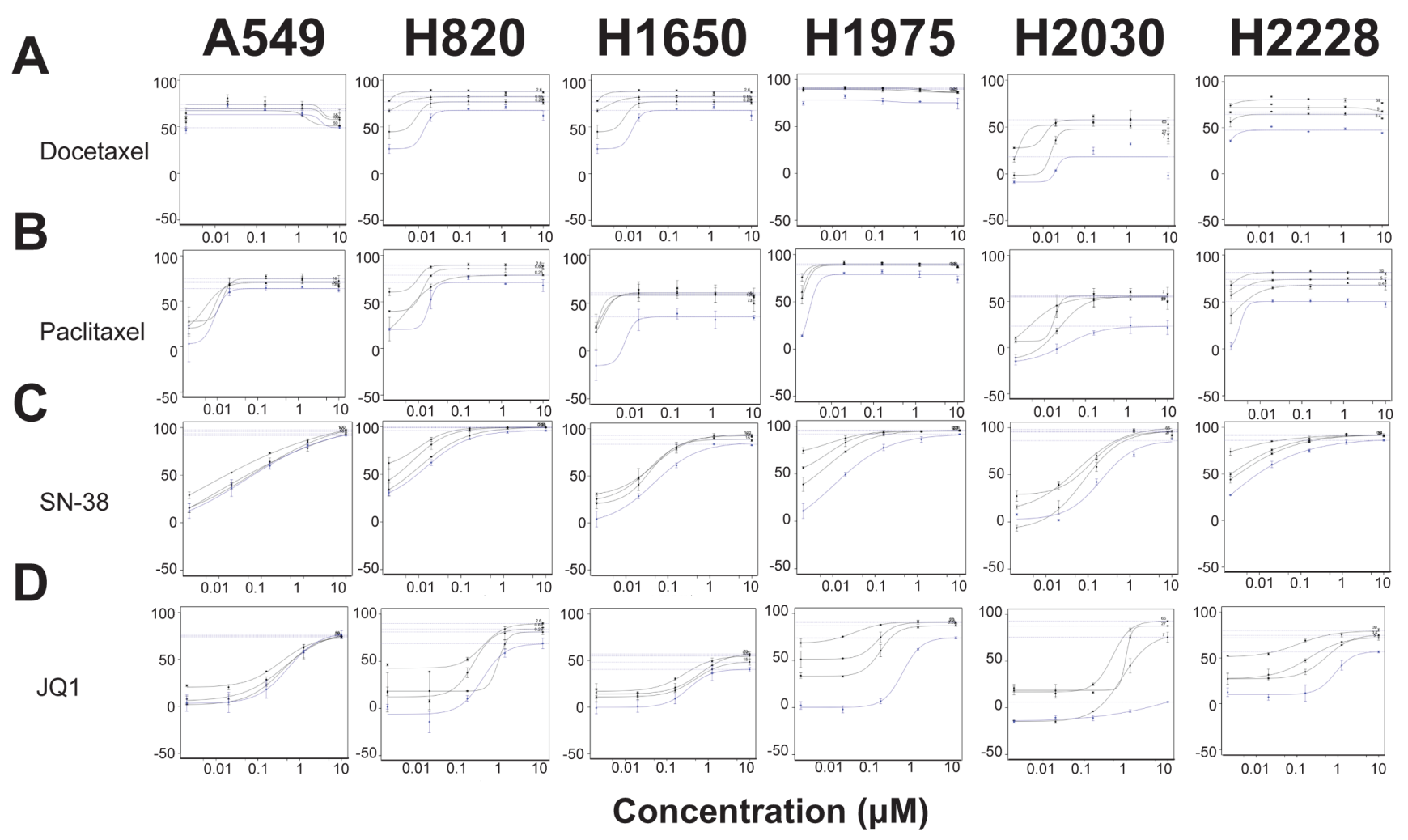

Figure 2: Taxanes, topoisomerase inhibitors, and bromodomain inhibitors sensitize lung adenocarcinoma cell lines to Debio 1143 treatment. Growth inhibition curves of docetaxel A., paclitaxel B., SN-38 C., and JQ1 D. in combination with Debio 1143. Blue curves indicate growth inhibitory response to docetaxel, paclitaxel, SN-38, or JQ1 in each respective cell line. The three black curves indicate the response to the combination of each respective agent and Debio 1143 in each cell line. Growth inhibition is plotted along the $\mathrm{y}$-axis of each graph. Debio 1143 concentrations used for each cell line are found in Table 1. 
metabolic and epigenetic modulators, and conventional chemotherapeutics. An Area Under the Curve (AUC) metric quantified the impact of combinations that inhibited growth more effectively and/or more potently than either single agent. The top $20 \%$ of partner agents ranked by AUC (Table S1) include several candidates that are in clinical trials or are already US FDA-approved (Table 2). Microtubule stabilizers, such as docetaxel (Figure 2A) and paclitaxel (Figure 2B) were some of the highest scoring compounds across the panel of six cell lines screened in combination with Debio 1143. Topoisomerase inhibitors, such as SN-38 (Figure 2C) or topotecan (Figure S2A), also scored highly using the AUC metric. Broadly acting small molecules, such as triptolide, JK184, gemcitabine, MS275 (HDAC inhibitor), and bortezomib (data not shown) also gave robust additive responses in the sensitization screen. A subset of lung adenocarcinoma cell lines was also sensitive to bromodomain inhibition with both iBET (Figure S2B) and JQ1 (Figure 2D).

Three of the cell lines have EGFR driver mutations but are resistant to EGFR inhibition through the common T790M resistance mutation (H1975, and H820, which is also MET-amplified,) or other mechanisms (H1650). These cell lines were more sensitive to several receptor tyrosine kinase inhibitors, including the broad kinase inhibitors dasatinib and foretinib. The third-generation EGFR inhibitor, afatinib (BIBW-2992), combined superadditively with Debio 1143 to inhibit growth of mutant EGFR lung adenocarcinomas. Debio 1143 sensitized cells to co-treatment with a second agent for one of the two mutant KRAS cell lines in the screen - H2030. This is especially interesting as $\mathrm{H} 2030$ is relatively resistant to approximately 100 single agents that we tested with a broad range of targets (data not shown). Debio 1143 sensitized H2030 cells to inhibition of Polo-like kinase, PI3 kinase, MEK, and BCL-2 family members (data not shown). Other combinations with Debio 1143 were no more effective than either agent alone, or were antagonistic. They included receptor tyrosine kinase inhibitors, such as AZD-4547, sunitinib, and crizotinib. AKT inhibition also did not sensitize cells to Debio 1143 treatment. Taken together, the screen revealed several combinations with enhanced growth inhibitory activity on a variety of lung adenocarcinoma cell lines, as well as several combinations that did not enhance growth inhibition.

\section{Synergistic Debio 1143 combinations}

Synergistic growth inhibition could not be determined with the small number of dose points used initially, but can be formally evaluated by calculating combination index values [26]. We were particularly interested in the taxanes as they were among the highest scoring combinations by the AUC metric, and because the combination of Debio 1143 with paclitaxel and carboplatin is in clinical trials for squamous non-small cell lung cancer, platinum-refractory ovarian cancer, and triple-negative breast cancer (NCT01930292). Debio 1143 was more effective and potent at inhibiting growth in combination with either paclitaxel (Figure 3A) or docetaxel (Figure 3B). Debio 1143 was also more effective in combination with SN-38 (the active metabolite of irinotecan) or with the bromodomain inhibitor JQ1 (Figure 3C and 3D, respectively). Almost all combinations tested in Figure 2 were synergistic based upon the ChouTalalay combination indices derived from the curves in Figure 3A-3D. The only exception was the combination of Debio 1143 and SN-38 in H2030 cells; this interaction was additive, but not synergistic.

We next evaluated the effects of these three combinations on cell clonogenicity. Debio 1143 reduced clonogenicity of H1975 and H2030 cells, but not A549 cells, consistent with the original screening data (Figure S3). Debio 1143 in combination with all three agents substantially reduced clonogenicity compared to vehicletreated cells. This included A549 cells, which were resistant to Debio 1143 as a single agent (Figure S3).

Debio 1143, alone and in combinations, could affect cell accumulation and clonogenicity through impact on cell proliferation and/or on cell survival. Over a period of 24 hours, Debio 1143 alone induced moderate polyADP ribose polymerase (PARP) cleavage in H1975 and H2030 cells; cleaved PARP levels were greatly enhanced in the presence of paclitaxel, SN38, or JQ1 in H1975 and H2030 cells (Figure 3E, 3F, and 3G). Debio 1143 induced no PARP cleavage in A549 cells, which are resistant to this agent in CellTiterGlo and clonogenic growth assays. In A549 cells, the extent of PARP cleavage in combinations was similar to that induced by the single partner agents. The impact of longer-term 72 hours treatment on apoptosis was determined by Annexin V/propidium iodide flow cytometry. Debio 1143 plus JQ1 induced apoptosis in the combination-sensitive lines H1975 and H2030, but not the combination-resistant line A549 (Figure3H). Overall, Debio 1143 is effective as a single agent and induces apoptosis in combination with compounds with diverse mechanisms of action.

\section{Signaling impact of Debio 1143 and JQ1 co- treatment}

Modulation of PI3K and MAPK signaling has shown benefit in lung adenocarcinoma cell lines. Cotreatment with Debio 1143 and JQ1 reduced pAKT(S473) and p70S6K (phospho and total) in H2030 and A549 cells, but not in H1975 (Figure S4). The Debio 1143/ JQ1 combination reduced pERK in A549 and H2030, but increased pERK in H1975 cells (Figure S4). Hence, sensitivity to Debio 1143 plus JQ1 was not tightly correlated with PI3K or MAPK signaling in these lines. 
A

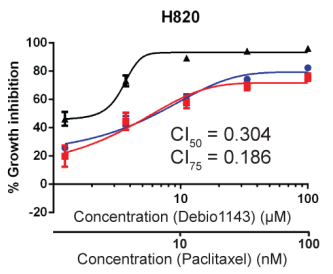

B

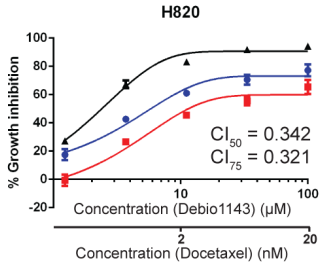

C

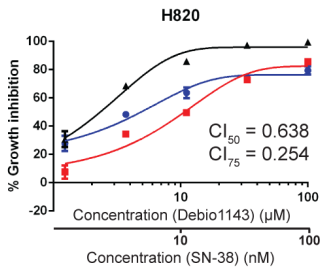

D
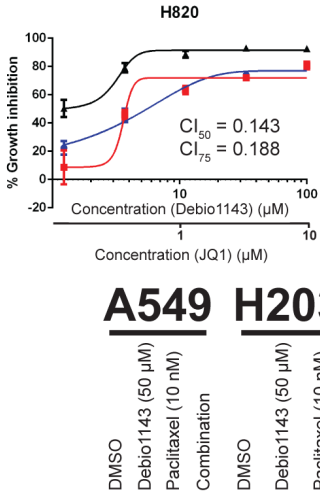

E
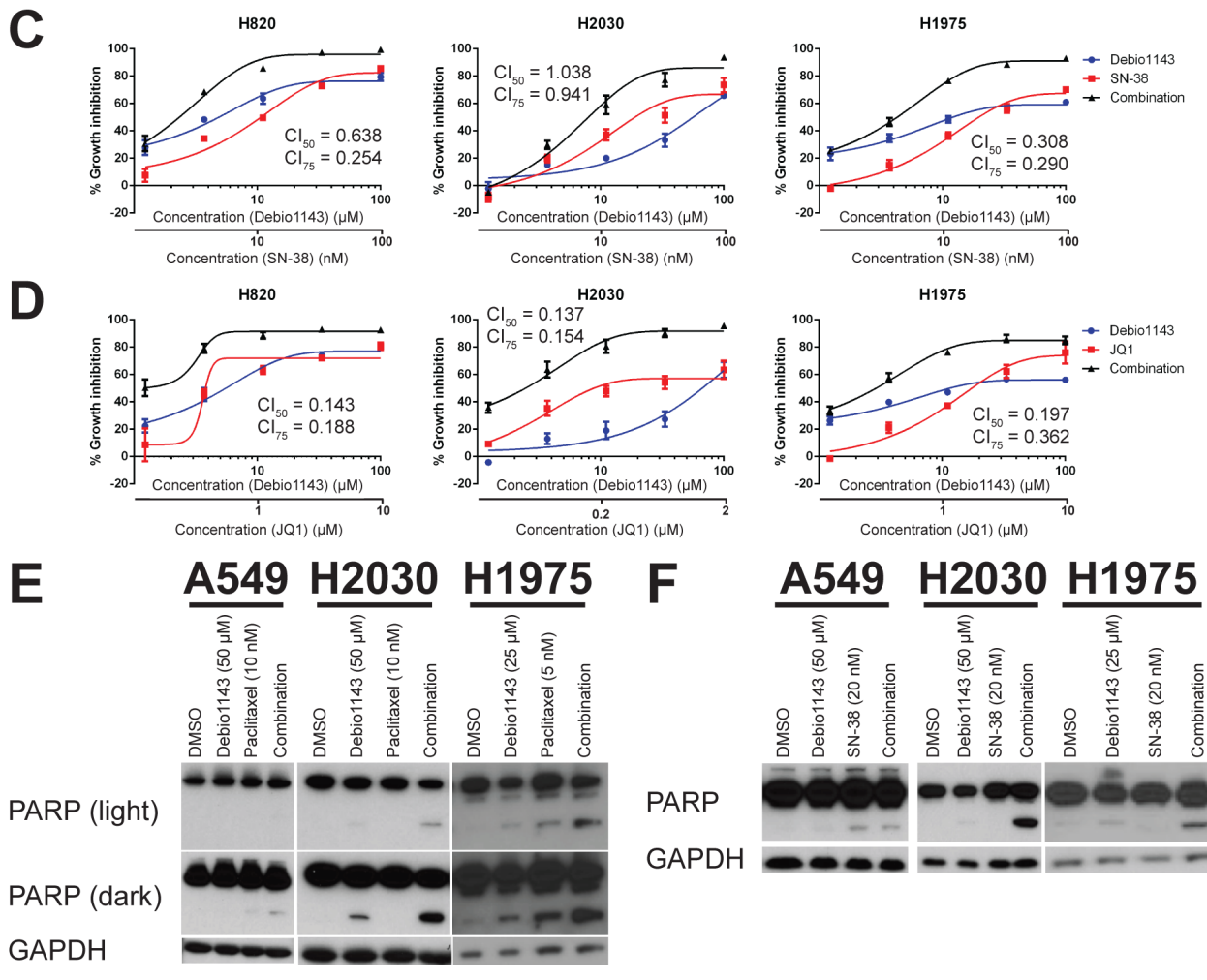

H1975 F

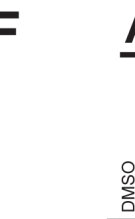

A549 $\mathrm{H2030}$

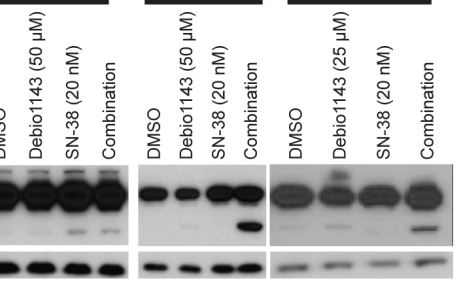

GAPDH

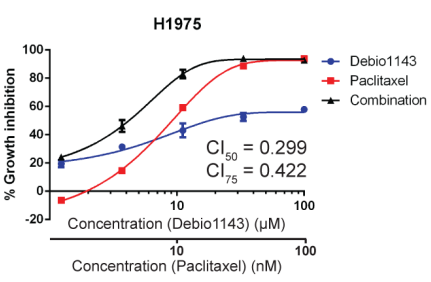

- Debio1143

- Docetaxel
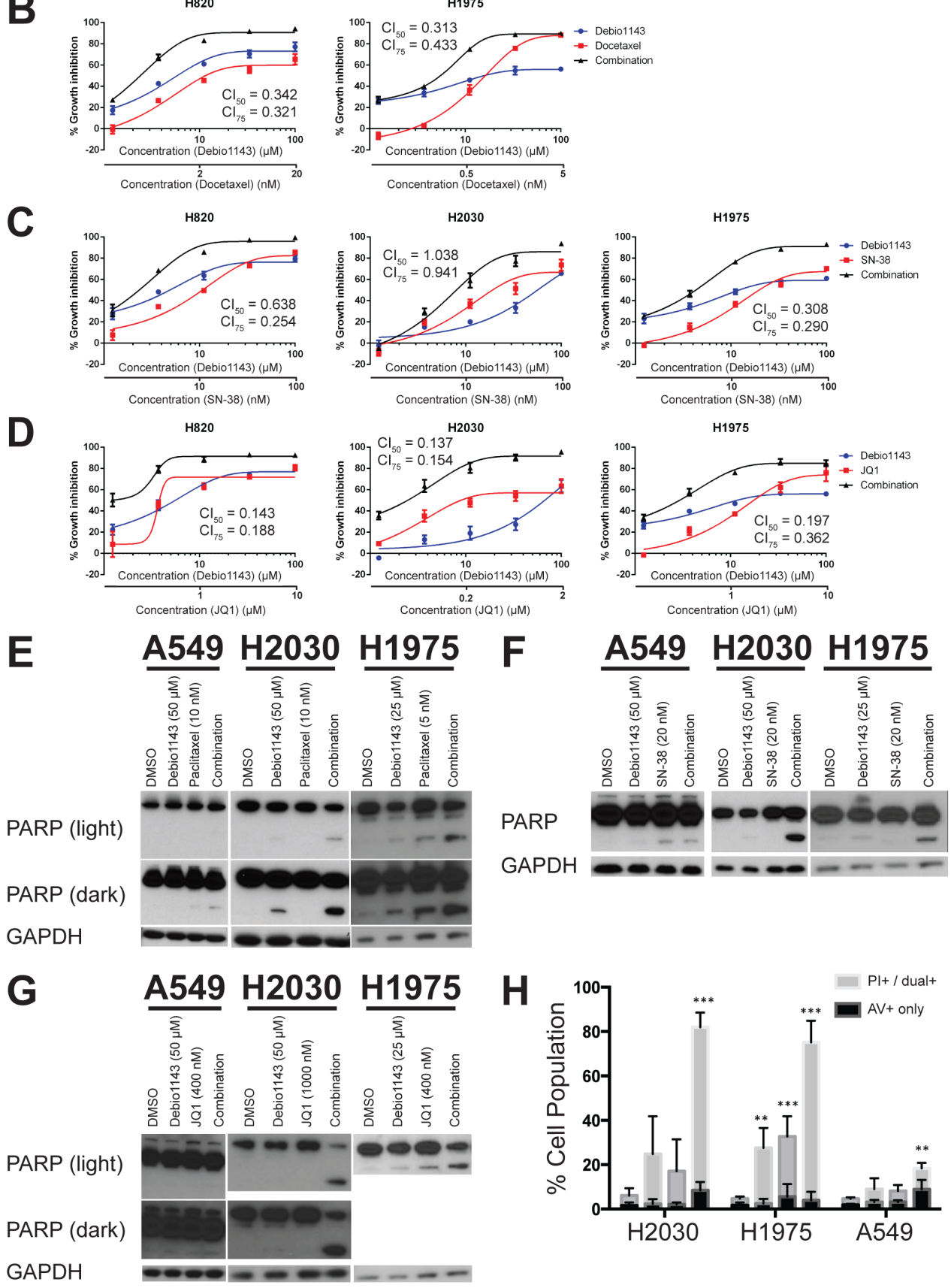

Figure 3: Debio 1143 synergizes with several agents to inhibit growth of lung adenocarcinoma cell lines and induce apoptosis. A.-D. Fixed-concentration growth inhibition assays were performed with four different Debio 1143-containing combinations - A. Debio 1143 and paclitaxel; B. Debio 1143 and docetaxel; C. Debio 1143 and SN-38; D. Debio 1143 and JQ1. (E-G) Immunoblots with indicated primary antibodies following treatment with Debio 1143 and paclitaxel E., SN-38 F., or JQ1 G. combinations. H. Annexin V/propidium iodide flow cytometry following Debio 1143 and/or JQ1 treatment. Annexin V (AV+) only stained cells considered early apoptotic. Propidium iodide-only stained plus dual Annexin V- and propidium iodide-stained positive cells considered late apoptotic. Both early and late apoptotic populations added together for statistical purposes. ${ }^{* *} p<0.01, * * * p<0.001$. H1975 = Debio $1143(25 \mu \mathrm{M}), \mathrm{JQ} 1$ $(400 \mathrm{nM}) ; \mathrm{H} 2030$ = Debio $1143(50 \mu \mathrm{M})$, JQ1 $(1 \mu \mathrm{M}) ;$ A549 = Debio $1143(50 \mu \mathrm{M})$, JQ1 (400 nM). 
Table 2: Top 27 agents in all cell lines, or either mutant EGFR or KRAS lung adenocarcinoma cells, that best sensitized cells to Debio 1143 according to AUC metric.

\begin{tabular}{|c|c|c|c|c|c|}
\hline \multicolumn{2}{|c|}{1143 all cell lines top 27} & \multicolumn{2}{|c|}{1143 EGFR } & \multicolumn{2}{|c|}{$1143 \mathrm{KRAS}$} \\
\hline Compound & Target & Compound & Target & Compound & Target \\
\hline Pachlaxel & microlubule & Pachlaxel & microlubule & Flawepiridel & CDKs \\
\hline Triptolide & NFKB,CIAP & Homoharringtonine & protein symithesis & $\overline{\mathrm{B}-2536}$ & PLK \\
\hline$\sqrt{K} 184$ & Gע, microtubules & JK 164 & GШ, microtubules & Ahtomycin C & micratubule \\
\hline BI-2536 & PUK & Vhovelibine & inicrolubule & Obaloclax & BCL2 \\
\hline Wmorebine & microtubule & Topodecan & topoisomerawe & JK 184 & $\mathrm{CU}_{\mathrm{B}}$ microtubudes \\
\hline Topotecen & topoiscmerase & Docotaxel & microtubule & Paditaxel & mierotubule \\
\hline Docelandel & microlubule & KP'372-1 & PDK1/AKTSFT & Fensigolimuss" & ImTOR \\
\hline $\mathrm{KP} 372-1$ & |PDK1/AKTIFLT & SN3B & topoisomeraes & Worimastat"s & HDAC \\
\hline Flavopiridd & CDKs & Triptolide & NFKB,CIAP & Bortezoming & proteasome \\
\hline \$स 438 & Lepoisomerasse & Genncilaturine & nucleoside unalog & Fequamesin" & ImTOR \\
\hline Bortezoming & prolesisome & B1-25286 & FLK & Triplailide & NFHB,CIAP \\
\hline Gemclabine & nucleoside analog & Foretin b & WET/AXLNEGFR & Vinorelline* ${ }^{*}$ & microtubule \\
\hline Hownof raminglonine & prolein synth & 17-DMAG & HSPMO & MS-275 & HDAC1,3 \\
\hline Daseinth & Abl, Src & GDC-0941 & PI3K & SB 218078 & Chkt \\
\hline Dacinomych & transcription & MLN-8237 & Aurcora & CIP $13-74$ & MEKK \\
\hline GDC-0941 & PISIK & ABT-203 & Bid-2 faumily & Triapine & Iibonuckedide reductasse \\
\hline MS-275 & HDAC 1,3 & Dasalinb & Abl, Brc & Homoharringtonine & protein synth \\
\hline MD 0354 & |1KK-2 & IND 0354 & IIKK2 & JQ1 & bromodomain \\
\hline AZD-7762 & CHK $1 / 2$ & Flavepiridol & CDKs & Vandolerabo & EGFRNEGFRRET \\
\hline Forelinib & METAXLNEGFR & MK-17/5 & WEET & STA-4723 & ROS,pro-apoptasis \\
\hline MLN-8237 & Aufrora & Dactinomincin ${ }^{*}$ & transcription & Topotecan & topoisomerase \\
\hline NVP-TAE684 & ALK & B.BW-2932 & EGFRERBB2 & $\mathrm{A} Z \mathrm{D}-\pi 762$ & CHK1/2 \\
\hline ABT-263 & BCGL2 family & Eorteranomin: & proilessome & |16P72-1 & FLKIIAKTFLT \\
\hline MK-177 & WEE $\uparrow$ & Digoxin & NaKATPase & BEZ-235 & PIIKMTOR \\
\hline J01 & bromodomain & PF 431396 & FAKIPYKR & Doceghaxed & mitrolubule \\
\hline BMBW-2992 & EGFR/ERAB2 & $\mathrm{HBX}-4110 \mathrm{~s}$ & USP7 & Tozaserfib & Aurora \\
\hline PF 431398 & FAK.PYK2 & Cantileomion & proteasome & GSK1120212 & MEK Trametinib \\
\hline Comporund & קc & dare FDA & & & \\
\hline
\end{tabular}

SMAC mimetics and bromodomain inhibitors modulate the NF- $\kappa$ B pathway $[5,6,12]$. We evaluated the impact of Debio 1143 and JQ1, alone or in combination, on the canonical and non-canonical arms of the NF- $\kappa \mathrm{B}$ pathway. The combination, but neither single agent, elevated $\mathrm{I} \kappa \mathrm{B} \alpha$, an $\mathrm{NF}-\kappa \mathrm{B}$ inhibitor (Figure 4A). Activity of the non-canonical and canonical NF- $\kappa \mathrm{B}$ pathway is marked by nuclear localization of effectors p52 and p50, respectively. Debio 1143, but not JQ1, induced nuclear localization of p52 in each cell line tested - H1975, A549, and $\mathrm{H} 2030$, with no augmentation by the combination (Figure 4B, 4C, and 4D). Debio 1143 induced nuclear localization of p50 in all three cell lines (Figure 4B, 4C, and 4D). However, the combination restored nuclear p50 protein levels to baseline levels in H1975 cells (Figure 4B). The combination only slightly decreased nuclear p50 protein levels in combination-treated A549 cells (Figure 4C). Furthermore, an increase in p50 nuclear localization was seen from vehicle-treated to Debio 1143-treated cells and Debio 1143-treated cells and combination-treated H2030 cells (Figure 4D). Hence, combination of Debio 1143 and JQ1 induces the non-canonical NF- $\kappa$ B signaling cascade, and canonical NF- $\mathrm{NB}$ signaling is repressed to baseline levels following combination treatment in the combination-sensitive H1975 cell line.
Debio 1143 and JQ1 combination reduces IAP levels and induces ripoptosome formation

SMAC mimetics function by inhibiting and promoting destruction of IAPs [12-14]. In H1975, H2030, and A549 cells, Debio 1143 nearly completely ablates cIAP1 (Figure 5A, Figure S5A). JQ1 also moderately reduces cIAP1 levels in H1975, A549, and H2030 cells. Protein levels of cIAP1 are undetectable in the Debio 1143/JQ1 combinations (Figure 5A, S5A). Debio 1143 can also bind cIAP2 and XIAP levels but not to the extent seen for cIAP1 [27]. cIAP2 and XIAP levels were most completely suppressed following combination treatment with Debio 1143 and JQ1 in H1975 cells (Figure 5A). In H2030 cells, XIAP levels were reduced below baseline levels following JQ1 and combination treatment (Figure $\mathrm{S} 5 \mathrm{~B})$. The reduction in XIAP levels was surprising since XIAP levels are not usually affected by SMAC mimetics $[7,11]$. cIAP2 levels were also reduced following JQ1 treatment, but some rebound in cIAP2 protein levels was seen in combination-treated H2030 cells (Figure S5B). cIAP2 levels were also suppressed in A549 cells following the combination treatment, but there was little impact on XIAP (Figure S5B). Together, these data indicate that suppressing several IAPs is associated with greatest growth inhibition of lung adenocarcinoma cells.

SMAC mimetics can induce expression of TNF $\alpha$, 
which activates the NF- $\mathrm{BB}$ pathway $[12-14,28]$. Furthermore, JQ1 pleiotropically reduces expression of many transcripts including MYC and FOSL1 [29-32]. Debio 1143 enhanced TNF $\alpha$ mRNA expression in H2030 cells, but not H1975 or A549 (Figure 5B), and JQ1 did not affect $T N F \alpha$ mRNA expression. However, baseline expression of $T N F \alpha$ mRNA was significantly higher in H1975 cells than the other two lines (Figure 5C). FOSL1 transcription was reduced by JQ1 treatment in JQ1sensitive cell lines, but no further decrease was observed following combination treatment with Debio 1143. Instead, Debio 1143 increased expression of FOSL1 in all lines tested regardless of sensitivity to the agent (Figure S6A). Consistent with other reports for lung adenocarcinoma, JQ1 had little impact on MYC mRNA (Figure S6B) [32]. Overall, we found no correlation between Debio 1143 response, JQ1 response, or combination response and change in expression of the genes tested. We also found no association with response to Debio 1143, JQ1, or the combination and histone $\mathrm{H} 3$ lysine-27 acetylation or pan-

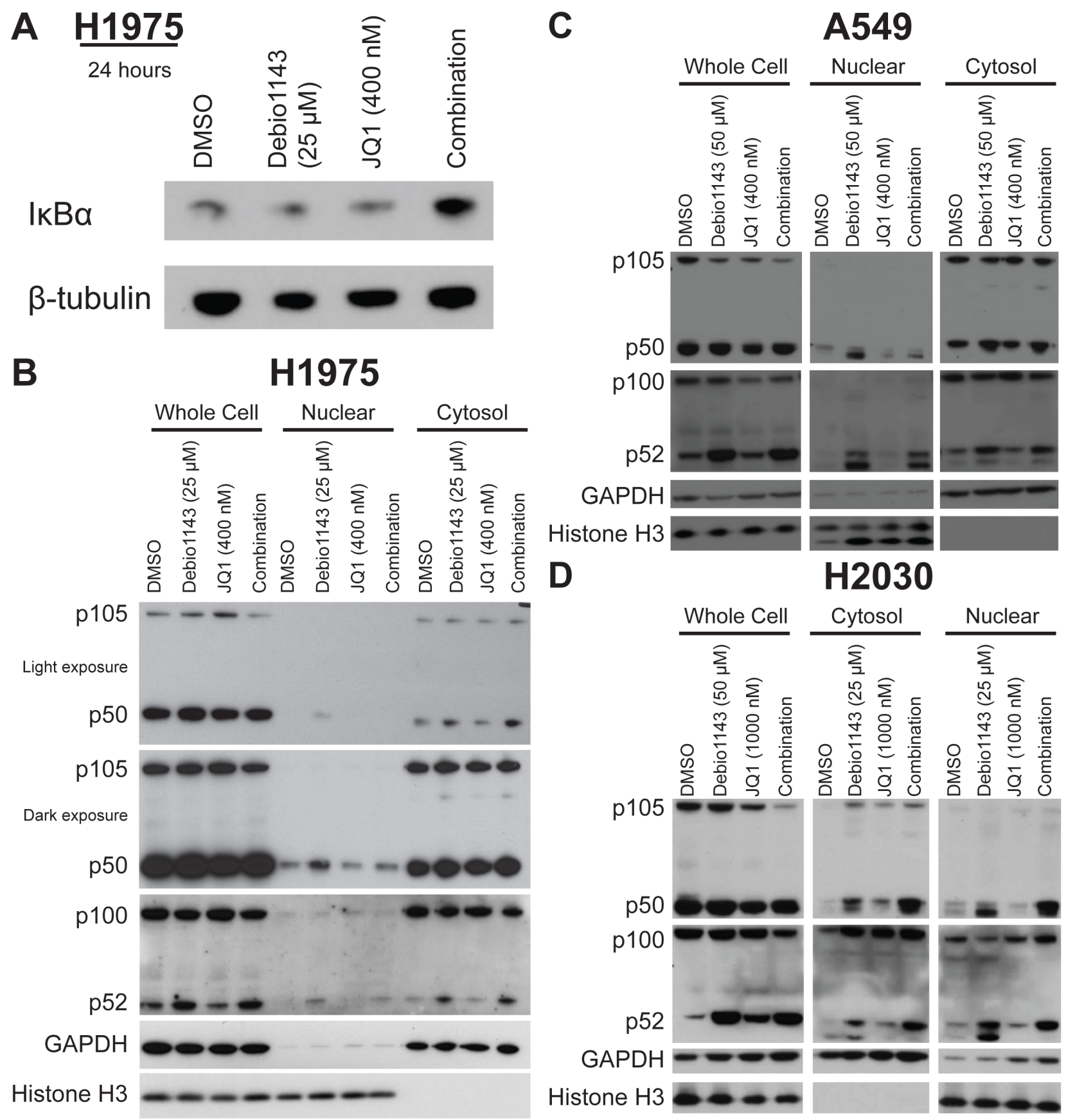

Figure 4: Debio 1143 and JQ1 treatment activates NF-кB signaling. A. Immunoblots of IкB $\alpha$ protein levels in H1975 cells after 24 hour treatment. Cellular fractionation of B. H1975, C. A549, and D. H2030 cells following 24 hour treatment with Debio 1143 and/or JQ1. Immunoblots with canonical and non-canonical NF- $\mathrm{B}$ signaling components. 


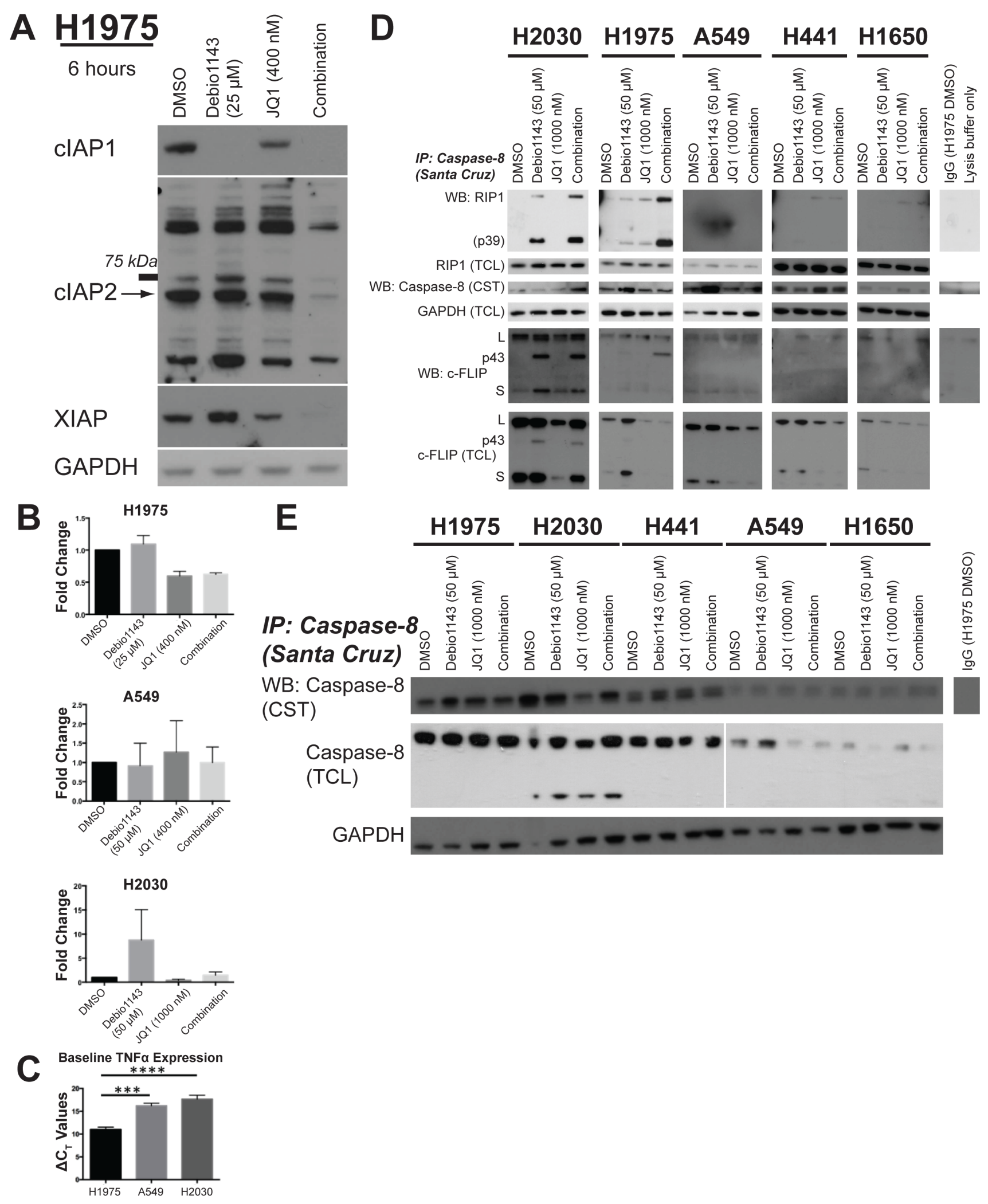

Figure 5: Debio 1143 and JQ1 co-treatment reduces IAP levels and leads to formation of the ripoptosome. A. Immunoblots of IAP protein levels following 6 hours of treatment with Debio 1143 and/or JQ1. Arrow indicates band of correct molecular weight for cIAP2. B. $T N F \alpha$ mRNA expression following 6 hour treatment with Debio 1143 and/or JQ1.C. Baseline TNF $\alpha$ mRNA expression in H1975, A549, and H2030 cells. D. Immunoprecipitation of caspase- 8 followed by immunoblots of ripoptosome components to measure formation of the ripoptosome following Debio 1143 and/or JQ1 treatment. Cleavage product of RIP1 (p39) indicates active ripoptosome. Cleavage product of c-FLIP (p43) indicative of caspase- 8 activity and functional ripoptosome. E. Immunoblot of procaspase- 8 protein levels. 
acetylation of histone H4 (Figure S6C).

TNF $\alpha$ induces formation of the ripoptosome, a celldeath inducing complex that controls both apoptotic and necrotic cell death $[16,17]$. Caspase-8 and RIP1 (RIPK1) are ripoptosome components. In Debio 1143-sensitive H2030 and H1975 cells, Debio 1143 alone strongly promotes co-immunoprecipitation of RIP1 and c-FLIP (especially p43) with caspase-8; this is indicative of ripoptosome formation. Further increases in RIP1 and caspase- 8 co-immunoprecipitation were seen following combination treatment (Figure 5D). Both the p39 cleavage product of RIP1 and the p43 cleavage product of c-FLIP ${ }_{L}$ co-immunoprecipitated with caspase-8, marking a functional ripoptosome $[17,33]$. In contrast, co-immunoprecipitation of caspase-8 with RIP1 was not observed in three Debio 1143-insensitive cell lines - H441, H1650, and A549 (Figure 5D).

Total levels of c-FLIP isoforms (c-FLIP $_{L}$ and c-FLIP ${ }_{\mathrm{S}}$ ) were reduced following JQ1 and combination treatment in four of the lines tested regardless of sensitivity to Debio 1143. In H2030 cells, only JQ1-treated cells showed decreased c-FLIP protein levels, not combinationtreated H2030 cells (Figure 5D). However, total cell lysate increases in c-FLIP ${ }_{\mathrm{p} 43}$ levels were also observed in H2030 cells treated with JQ1 (alone or in combination with Debio 1143) (Figure 5D). Combined, these results indicate a functioning ripoptosome is formed in the two cell lines most sensitive to the combination of Debio 1143 and JQ1. Also, inhibition of ripoptosome formation is removed even in Debio 1143-insensitive lines following JQ1 treatment. Procaspase-8 levels do correlate with greatest response to the combination of Debio 1143/JQ1 combination. Of the five lines tested for ripoptosome formation, the three lines with highest baseline caspase-8 levels were the most sensitive to the combination (Figure 5E). Although H441 is insensitive to Debio 1143 treatment, the combination of Debio 1143 and JQ1 super-additively inhibits growth more than either agent alone (Figure S7). Overall, ripoptosome formation correlates with Debio 1143 sensitivity and JQ1 reduces protein levels of anti-apoptotic c-FLIP. Debio 1143 and JQ1 combination sensitivity are more closely associated with baseline procaspase- 8 protein levels than with ripoptosome formation.

\section{Debio 1143-containing combinations inhibits xenograft growth of lung adenocarcinomas}

Xenografts of H1975 and A549 cells were implanted in nude mice to test the efficacy of Debio 1143 in combination with either JQ1 or docetaxel. Limited effects of the combination of Debio 1143 and JQ1 treatment on tumor volume were observed in $\mathrm{H} 1975$ xenografts treated with $30 \mathrm{mg} / \mathrm{kg}$ Debio $1143 ; 25 \mathrm{mg} / \mathrm{kg}$ JQ1 (maximum $\%$ treated/control $[\% \mathrm{~T} / \mathrm{C}]=52.7 \%$ ) (Figure $6 \mathrm{~A}$ ). At these drug concentrations, body weights were reduced early in treatment, indicative of toxicity, but body weights stabilized over time (Figure 6B). Pro-inflammatory dose limiting toxicity was observed at higher doses of each agent (data not shown). In contrast, little overt toxicity was observed for the combination of Debio 1143 and docetaxel at $100 \mathrm{mg} / \mathrm{kg}$ Debio $1143 ; 8 \mathrm{mg} / \mathrm{kg}$ docetaxel (Figure 6D), which was highly effective on A549 xenografts (maximum $\% \mathrm{~T} / \mathrm{C}=20.5 \%$ ) (Figure $6 \mathrm{C})$.

\section{DISCUSSION}

Drug combination treatments are essential for more effective cancer therapies. Here, we describe a combination screen of the SMAC mimetic Debio 1143 with 128 other agents against a panel of lung adenocarcinoma cell lines. Sensitivity to Debio 1143 was not associated with any mutational genotype. Debio 1143 in combination with the microtubule stabilizer paclitaxel, topoisomerase inhibitor SN-38, or the bromodomain inhibitor JQ1 synergistically inhibited growth and clonogenicity, and induced apoptosis in lung adenocarcinoma cells. Debio 1143 reduced levels of cIAP1 in all lines tested and variably affected other IAPs. Debio 1143 also modulated NF-KB signaling with increasing nuclear localization of p52 (non-canonical signaling). Debio 1143/JQ1 combination treatment impaired canonical p50 nuclear localization in the most Debio 1143-sensitive cell line tested. Furthermore, the combination of Debio 1143 and JQ1 induced formation of the cell-death inducing ripoptosome complex. Procaspase- 8 protein levels most closely correlated with sensitivity to the combination of Debio 1143 and JQ1. Debio 1143 in combination with JQ1 or docetaxel gave modest to robust in vivo growth inhibition, respectively, in lung adenocarcinoma xenografts.

Cell cycle and checkpoint inhibitors, such as the pan-cyclin dependent kinase (CDK) inhibitor flavopiridol and polo-like kinase inhibitor 1 (PLK1) BI-2536 among others, were among the most effective combination partners with Debio 1143 in our combination screen. These targets are important in maintaining mutant $K R A S$ lung adenocarcinomas $[34,35]$ suggesting that relieving some cellular anti-apoptosis restraints with SMAC mimetics may be effective in concert with some of these therapies. Tyrosine kinase inhibitors also combined effectively with Debio 1143 in our sensitization screen. Two cell lines with T790M EGFR gatekeeper mutations were especially sensitive to combinations with Debio 1143 and either afatinib, foretinib, or dasatinib. Foretinib can inhibit MET and TAM family receptors (TYRO3, AXL, MERTK) [36]. MET is indicated as a source of resistance to EGFR inhibitor therapy and crosstalk with EGFR can modulate signaling $[22,37]$. TAM family receptors are also implicated as resiliency receptors that bypass EGFRtargeted therapy [38]. Dasatinib inhibits Src-family kinases implicated in driving EGFR-independent resistance mechanisms to EGFR inhibitors [37]. Debio 1143 in 
combination with MEK inhibition also had great effects on $K R A S$ mutant cell lines. MEK inhibitor combinations have shown promise for $K R A S$ mutant tumors [39].

IAPs are E3-ubiquitin ligases expressed at high levels in cancer [1]. SMAC mimetics induce conformational changes in cellular IAPs leading to auto-ubiquitination and proteasomal degradation [1214]. Debio 1143 binds the BIR3 domain of cIAP1 and cIAP2 more strongly than XIAP [27]. We found that Debio 1143 reduces cIAP1 levels as a single-agent and in combinations, regardless of the growth sensitivity of cell lines to Debio 1143. Therefore, cIAP1 reduction is not sufficient to promote apoptosis. Debio 1143 variably reduced XIAP and cIAP2, but all three IAPs were suppressed in the most sensitive line, H1975.

Other SMAC mimetics induce non-canonical and canonical NF- $\mathrm{KB}$ signaling, which was confirmed as well for Debio 1143 [5, 6, 12]. Loss of the cellular IAPs increases protein levels of NF- $\kappa \mathrm{B}$-inducing kinase (NIK), facilitating the activity of the non-canonical NF$\kappa \mathrm{B}$ signaling pathway $[12,40]$. Induction of canonical $\mathrm{NF}-\kappa \mathrm{B}$ signaling radiosensitizes glioblastoma cells and can differentiate glioblastoma stem-cell-like cells [19, 41]. Furthermore, SMAC mimetic-treated pancreatic adenocarcinoma cells rely on canonical NF- $\kappa \mathrm{B}$ signaling to be sensitized to gemcitabine [42]. Activation of the canonical NF- $\kappa$ B pathway by SMAC mimetics leads to increased $T N F \alpha$ mRNA expression [12-14, 28]. The SMAC mimetic sensitive cell lines had strong baseline $T N F \alpha$ expression (H1975), or TNF $\alpha$ was strongly induced in another (H2030). Increased activity of these pathways cannot fully explain the pro-apoptotic effects of Debio 1143 because these pathways are active in Debio 1143-insensitive cells. Therefore, other mechanisms are behind the activity of Debio 1143 in this panel of lung adenocarcinoma cell lines tested.

Beyond increased NF- $\kappa \mathrm{B}$ activity, SMAC mimetic treatment and IAP depletion induces ripoptosome formation $[16,17]$. Depletion of IAPs causes a TNF $\alpha$ independent accumulation of RIP1 within the cytosol; this accumulation of RIP1 serves as a scaffold for ripoptosome formation $[16,17]$. In chronic lymphocytic leukemia cells, the inability to form ripoptosomes is linked to cell line resistance to SMAC mimetic treatment [43]. Furthermore, in acute lymphoblastic leukemia, ripoptosome components, such as RIP1, are required to induce cell death [44]. We found that Debio 1143 induces ripoptosome formation in Debio 1143-sensitive cell lines. The degree to which the cells form ripoptosomes following Debio 1143 treatment did not fully correlate with response to Debio 1143. H2030 is less sensitive to Debio 1143 than $\mathrm{H} 1975$, but H2030 had greater induction or ripoptosome

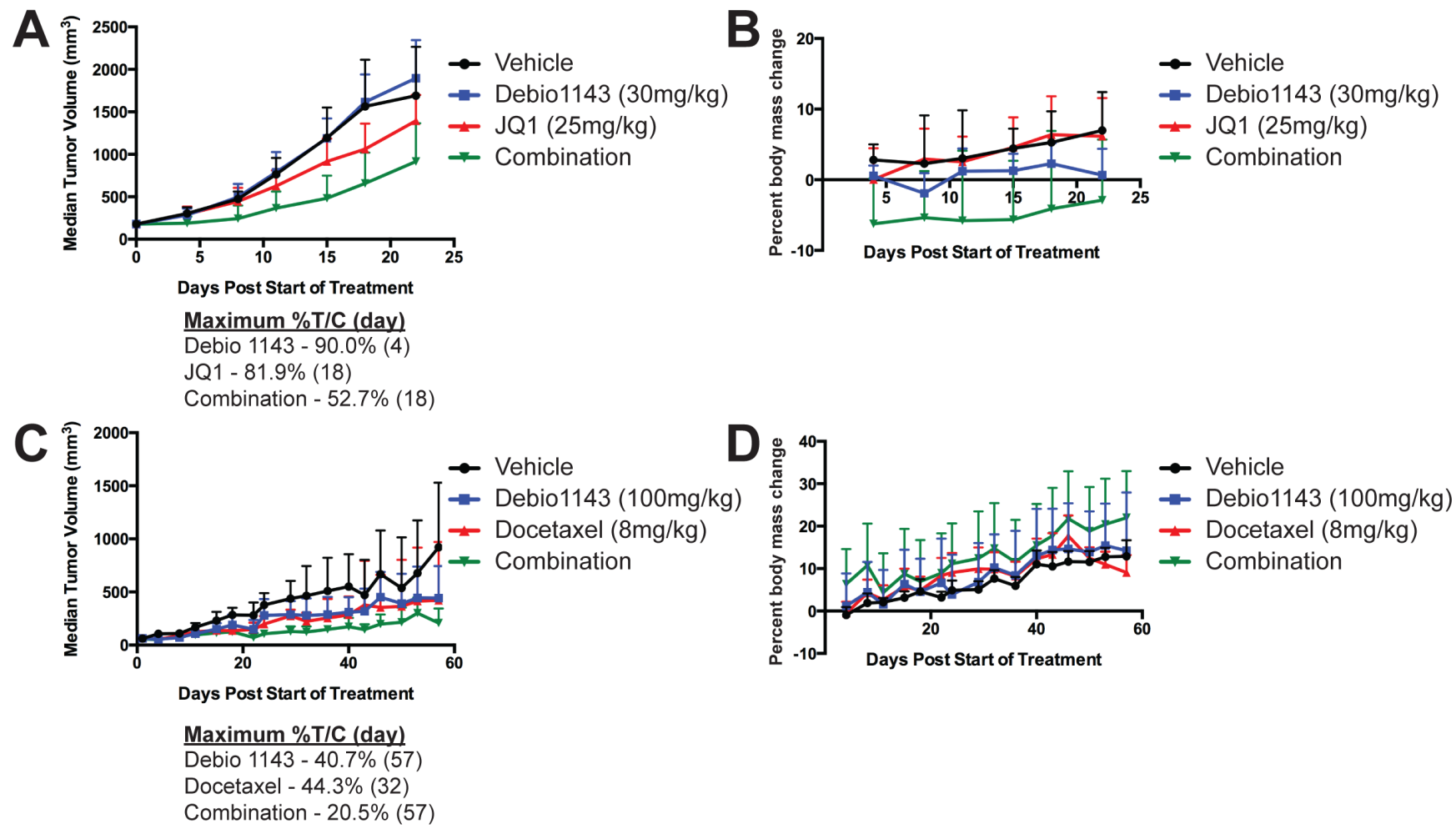

Figure 6: Debio 1143 in combination with either JQ1 or docetaxel delays growth of H1975 and A549 lung adenocarcinoma in xenograft mouse models. Median tumor volume of $\mathrm{H} 1975$ xenografts A. or percent body mass change B. following treatment with Debio 1143 (30 mg/kg p.o.) and/or JQ1 (25 mg/kg i.p.). Median tumor volume of A549 xenografts C. or percent body mass change D. following treatment with Debio 1143 (100 mg/kg p.o.) and/or Docetaxel (8 mg/kg, i.v.). Error bars are for standard deviation. Maximum percent tumor volume/control (\%T/C) for A. and C. also noted for each treatment arm. 
assembly than H1975 following Debio 1143 treatment. This suggests that the degree of ripoptosome assembly is less important than just forming the ripoptosome complex in order to induce cell death following SMAC mimetic treatment.

SMAC mimetics are excellent partner agents for combination therapies because they antagonize antiapoptotic proteins. Our combination sensitization screen uncovered several agents that super-additively combined with Debio 1143. Many of these combinations were confirmed to be synergistic and apoptosis-inducing, underscoring the notion that antagonizing IAPs results in chemosensitization.

Bromodomain inhibitors greatly enhance the effects of Debio 1143. Bromodomain inhibition leads to broad transcriptional and epigenetic changes with complex biological outcomes [29-32, 45]. KRAS-driven lung adenocarcinomas with wild-type $L K B 1$ are more sensitive to bromodomain inhibitor JQ1 than those with alterations in $L K B 1$ [31]. This pattern was observed in the three KRAS mutant cell lines tested in our panel. H441 has functional LKB1 and is sensitive to JQ1 treatment, whereas H2030 and A549 (non-functional LKB1) were less sensitive to JQ1 treatment. Furthermore, JQ1 sensitivity does not seem to correlate with $M Y C$ mRNA reduction, a common mechanism seen in other cancers [29, 30, 32]. Reduction in FOSL1 expression may be more likely facilitating the effects of bromodomain inhibition in these lung adenocarcinoma cells [32].

The closest association between Debio 1143 and JQ1 combination sensitivity and biological response was with components of the ripoptosome. Ripoptosome formation correlated with response to Debio 1143 as a single-agent, but not in combination as H441 cells were sensitive to the combination, but no ripoptosome formation was observed following combination treatment. Also, loss of both c-FLIP ${ }_{L}$ and c-FLIP $P_{S}$ ripoptosome components did not correlate with response to the combination. This is somewhat surprising given that ripoptosome formation is inhibited by c-FLIP ${ }_{L}$ and promoted by c-FLIP ${ }_{S}$, however, this is cell context specific $[17,46]$. The p39 cleavage product of RIPK1 and $\mathrm{p} 43$ cleavage product of c-FLIP ${ }_{L}$ are indicative of caspase- 8 activity $[16,33$, 47]. Caspase- 8 is the caspase responsible for facilitating ripoptosome-mediated cell death $[16,17]$. The most striking correlation we were able to see with Debio 1143 and JQ1 combination sensitivity was with baseline protein levels of procaspase-8. Procaspase- 8 protein levels are overexpressed in lung cancers [48]. JQ1 may be contributing to the effects of the combination mechanism by depleting c-FLIP levels. Depletion of c-FLIP has differential effects on lung adenocarcinoma cell lines, but caspase- 8 is necessary for lines to be sensitive to c-FLIP depletion [49]. By modulating these proteins it is possible to enhance sensitivity to SMAC mimetics.

We describe here the potential utility of Debio 1143 in combination with taxanes, topoisomerase inhibitors, or bromodomain inhibitors. The combination of Debio 1143 with both paclitaxel and carboplatin is in clinical trials for lung squamous cell carcinoma, platinumrefractory ovarian carcinoma, and triple negative breast cancer (NCT01930292). Other drug classes that combined effectively with Debio 1143 in our screen targeted cell cycle and checkpoint kinases, epigenetic modifiers, tyrosine kinases, and the NF- $\mathrm{KB}$ pathway. Hence the proapoptotic activities of Debio 1143 may enhance response to a broad range of therapeutic targets.

In vivo xenograft testing of some combinations confirmed modest activity of the combination of Debio 1443 and JQ1 and marked activity of the Debio 1143 and docetaxel combination for lung adenocarcinoma. With the Debio 1143 and JQ1 combination, there was some pro-inflammatory dose limiting toxicity observed. Inclusion of anti-inflammatory agents may ameliorate some of these effects. We also observed enhanced activity in A549 xenografts following Debio 1143 plus docetaxel treatment relative to the single agents. This is noteworthy as A549 cells were insensitive to this combination in our in vitro screen. SMAC mimetics have been reported to be more effective in vivo for treatment of pancreatic adenocarcinoma cell [28]. It is possible that systemic treatment of the whole mouse induces microenvironmental changes or alters paracrine signaling which further sensitizes the cells to combination treatment.

We have used sensitization screening to identify combination compound regiments with Debio 1143 to inhibit growth and induce apoptosis of lung adenocarcinoma cells. These combinations are excellent candidates for further therapeutic development as they include agents already in clinical use (taxanes, topoisomerase and MEK inhibitors, etc.) or novel agents with attractive targets and target interactions (bromodomain inhibitors). Our findings provide a rationale for the combination of Debio 1143 with paclitaxel in an ongoing clinical trial in several cancer types (ClinicalTrials.gov Identifier: NCT01930292). The especially strong impact of the combination of bromodomain inhibitors and SMAC mimetics warrants further investigation to identify the most important transcriptional targets, and the mechanisms that foster cooperation to induce cancer cell apoptosis.

\section{MATERIALS AND METHODS}

\section{Cell culture and antibodies}

Lung adenocarcinoma cell lines were cultured as described previously [22]. H1975, H2030, A549, H1650, and H441 were obtained from the American Type Culture Collection (ATCC). H2228 cells were a gift from J. Peter 
Koo (Yale). PC9, PC9/BRC1, H3255, and H3255 XLR were a gift from Katerina Politi (Yale). PC9/BRC1 and H3255 XLR cells are EGFR inhibitor resistant cells and have the EGFR T790M gatekeeper mutation [23].

Antibodies used include: PARP, phospho-p70S6K, p70S6K, phospho-AKT ${ }^{\text {Ser473 }}$, AKT, phospho-ERK, ERK, $\beta$-actin, caspase- 8 (mouse), p105/p50, and p100/p52 (Cell Signaling); RIP1 (BD Pharmingen); caspase-8 (goat), glyceraldehyde-3-phosphate dehydrogenase (GAPDH) (Santa Cruz); histone H3 (Abcam); c-FLIP (Enzo Life Sciences).

\section{Combinatorial compound screening (Figure 1A)}

Six cell lines were seeded at 1,000 cells per well in $16 \mu \mathrm{L}$ into 384-well plates using a MultiDrop Combi Reagent dispenser (Thermo). Plates were centrifuged at $1000 \mathrm{x} g$ to evenly disperse cells and cells allowed to adhere overnight. The following day, the cells were incubated with $20 \mathrm{~nL}$ each of 128 compounds using a PlateMate Plus automated pipetting system (MatrixTechCorp, Thermo). The 128 compounds were arrayed on two 384-well master plates with sixty-four agents in a five-point, eight-fold dilution series. The highest concentration was usually $10 \mu \mathrm{M}$ of compound.

After addition of the agents from the compound master plates, $4 \mu \mathrm{L}$ of either 1\% DMSO (vehicle control) or Debio 1143 diluted in medium at $5 \mathrm{X}$ the $\mathrm{GI}_{10}, \mathrm{GI}_{25}$, or $\mathrm{GI}_{50}$ concentrations was added. The concentrations of Debio 1143 were tailored according to experimentally determined GI values for each cell line. A MultiDrop Combi reagent dispenser (Thermo) distributed Debio 1143 or vehicle to each well. $20 \%$ DMSO was used as a complete growth inhibition control. Cells were treated in duplicate. $10 \mu \mathrm{L}$ of CellTiterGlo reagent was added to each well after seventy-two hours of incubation and luminescence was measured. All plates had Z'-scores of 0.5 or higher except for two plates with scores of 0.42 and 0.47 .

\section{Growth assays}

Cells were plated at $1,500-4,000$ cells in $100 \mu \mathrm{L}$ per well into 96-well black-bottom plates and allowed to adhere over night. The next day, cells were treated with respective compounds. Seventy-two hours later, $60 \mu \mathrm{L}$ CellTiterGlo reagent was added to each well and luminescence was measured to determine percent growth inhibition (\%GI).

Vehicle control was highest concentration of DMSO used in treatment conditions, between $0.1-0.3 \%(\mathrm{v} / \mathrm{v})$ DMSO. Complete growth inhibition signal control was 20\% (v/v) DMSO.

\section{Statistical analyses}

AUC measurements were performed as described previously [24]. Combination index (CI) values were calculated using CompuSyn software (ComboSyn) for the non-automated Chou-Talalay experiments [25].

\section{Colony formation assays}

400 cells were plated in six-well plates. Cells were treated the next day and then again three days later for a total of six days of incubation. Compounds were washed off the cells and allowed to grow five more days before being stained with $0.01 \%$ crystal violet.

\section{Flow cytometry}

250,000 cells were plated in each well of a sixwell tissue culture plate. After cells adhered overnight, they were treated with compound or DMSO vehicle for 72 hours. Next, adherent and non-adherent cells were collected, resuspended in annexin $\mathrm{V}$ binding buffer, and stained with both propidium iodide and annexin V-APC according to the manufacturer's protocol (BD Biosciences, San Jose, CA). Cells were analyzed using an LSRII flow cytometer.

\section{Cell fractionation}

Cells were incubated with compounds for 24 hours. Cells were washed twice with $1 \mathrm{X}$ Dulbecco's PBS (without magnesium or calcium) and then collected by scraping in a third wash of PBS. The cell solution was divided in half. Cells in both portions were collected by centrifugation. One of the pellets was lysed in 1\% SDS buffer $(40 \mathrm{mM}$ Tris $\mathrm{HCl}, \mathrm{pH} 7.4 ; 150 \mathrm{mM} \mathrm{NaCl}, 1 \%$ $\mathrm{SDS}, 10 \%$ glycerol), incubated at $100^{\circ} \mathrm{C}$ for 10 minutes, sonicated for 5 minutes (alternating pulses 15 seconds on, 15 seconds off) and cleared by centrifugation. The remaining cell pellet was washed once with RSB (reticulocyte standard buffer $[10 \mathrm{mM} \mathrm{NaCl}, 1.5 \mathrm{mM}$ $\mathrm{CaCl}_{2}, 10 \mathrm{mM}$ Tris $\mathrm{HCl}, \mathrm{pH}$ 7.4]) and re-centrifuged. The wash RSB was removed and the cells were then swelled on ice for 10 minutes in 10-20 volumes of RSB. The swollen cells were disrupted with a motorized Teflon pestle. The nuclei were pelleted at $1,000 \times \mathrm{g}$ for 5 minutes at $4^{\circ} \mathrm{C}$. The supernatant (cytosolic fraction) was removed. The nuclear fraction was washed three times more with RSB and resuspended in $1 \%$ SDS buffer. Nuclear fractions were incubated at $100^{\circ} \mathrm{C}$ for 10 minutes, sonicated, and cleared as described for whole cell extracts. Cytosolic fractions were cleared three times more by centrifugation, with the supernatant transferred after each clearing step. SDS and glycerol were added to a final concentration of $1 \%$ and 
$10 \%$, respectively, and cytosolic fractions were incubated at $100^{\circ} \mathrm{C}$ for 10 minutes. Comparable cell equivalent portions of nuclear and cytosolic fractions were analyzed by gel electrophoresis.

\section{RNA isolation and real-time PCR}

RNA was isolated and prepared for real-time PCR as described previously [22]. Fold changes were calculated using the $2^{-\Delta \Delta \mathrm{Ct}}$ method normalized to GAPDH transcript levels.

\section{Co-immunoprecipitation}

Cells were incubated for six hours with compounds. Cells were washed twice with 1X Dulbecco's PBS (without magnesium or calcium) and then lysed in immunoprecipitation lysis buffer $(20 \mathrm{mM}$ Tris- $\mathrm{HCl}, \mathrm{pH}$ 7.4; $150 \mathrm{mM} \mathrm{NaCl} ; 1 \%$ Triton X-100; 10\% glycerol; $0.5 \mathrm{mM}$ dithiothreitol; Roche Complete protease inhibitor cocktail). Approximately $500 \mu \mathrm{g}$ of protein was immunoprecipitated with $2 \mu \mathrm{g}$ of caspase- 8 (Santa Cruz) antibody or goat IgG (Santa Cruz) and $20 \mu \mathrm{L}$ of protein $\mathrm{A} / \mathrm{G}$ agarose beads (Thermo) with rotation at $4^{\circ} \mathrm{C}$ for two hours. Beads were washed four times with the lysis buffer. $45 \mu \mathrm{L}$ of $2 \mathrm{X}$ Laemmli sample buffer was then added to the beads and the samples were incubated at $100^{\circ} \mathrm{C}$ for 10 minutes.

\section{Western blotting}

Samples were resolved by gel electrophoresis and transferred to PVDF membrane. After blocking with $5 \%(\mathrm{w} / \mathrm{v})$ milk in $1 \mathrm{X}$ TBS-T $(0.1 \%$ Tween- 20$)$, cells were incubated overnight with indicated primary antibodies. Wash buffers were chosen according to the manufacturers' recommendations for each antibody. Appropriate species-specific horseradish peroxidaseconjugated secondary antibodies (Thermo) were added prior to chemiluminescence detection (Thermo West Pico or Femto).

\section{Xenografts}

Appropriate approval from the local institutions Animal Care and Use Committee was obtained and guidelines followed. H1975 $\left(2 \times 10^{6}\right)$ or A549 $\left(5 \times 10^{6}\right)$ cells, in $100 \mu \mathrm{L}$ Matrigel, were implanted subcutaneously in the right flanks of 6-8 or 4-6 week old, female Balb/c nude mice (Shanghai Laboratory Animal Co. LTD, Shanghai, China), respectively. Animals were randomized to groups of 8 animals with mean group tumor volumes of 150-200 $\mathrm{mm}^{3}$ and the treatments started the same day. Debio 1143 (Debiopharm International SA) was administered by oral gavage 5 days a week for 3 weeks either at $100 \mathrm{mg} / \mathrm{kg}$ (A549) or $30 \mathrm{mg} / \mathrm{kg}$ (H1975). Docetaxel (NorthCarolina Chemlabs) was administrated intravenously once a week for 3 weeks ( $8 \mathrm{mg} / \mathrm{kg}$ ). JQ1 (Abmole Bioscience Co., Limited, Hong Kong) was formulated in $10 \%$ hydroxypropyl- $\beta$-cyclodextrin (Sigma-Aldrich, \#C0926) and administered by intraperitoneal injection 5 days a week for 3 weeks at $25 \mathrm{mg} / \mathrm{kg}$. Tumor volume and mouse weight was monitored every 3-4 days. Tumor volume measured with the formula $V=l \times w \times w / 2$.

\section{ACKNOWLEDGMENTS}

The authors would like to thank the Yale Center for Molecular Discovery for their input during the sensitization screen. Special thanks to Janie Merkel and Mike Bohanon for their work on the screen. We also thank Samuel Katz for critical reading of the manuscript. This manuscript was used to fulfill in part the requirements for the degree of Doctor of Philosophy awarded to Casey Langdon by Yale University.

\section{CONFLICTS OF INTEREST}

NW, FL, and GV are employees of Debiopharm International SA. SW is a consultant for and owns stocks and stock options in Ascenta Therapeutics, which has outlicensed Debio 1143 to Debiopharm International SA. Stern and Bosenberg laboratories received funding from Debiopharm International SA to support this work. There are no other conflicts of interest.

\section{GRANT SUPPORT}

This work was supported by Debiopharm International SA. CGL was supported by NIH training grant T32GM007324. Yale Center for Molecular Discovery is supported in part by US National Cancer Institute grant P30 CA16359 awarded to Yale Cancer Center.

\section{Editorial note}

This paper has been accepted based in part on peerreview conducted by another journal and the authors' response and revisions as well as expedited peer-review in Oncotarget.

\section{REFERENCES}

1. Fulda S. Smac mimetics as IAP antagonists. Seminars in cell \& developmental biology. 2014.

2. Fulda S. Molecular pathways: targeting inhibitor of apoptosis proteins in cancer-from molecular mechanism to therapeutic application. Clinical cancer research : an official 
journal of the American Association for Cancer Research. 2014; 20:289-295.

3. Vucic D, Dixit VM and Wertz IE. Ubiquitylation in apoptosis: a post-translational modification at the edge of life and death. Nature reviews Molecular cell biology. 2011; $12: 439-452$

4. Bertrand MJ, Milutinovic S, Dickson KM, Ho WC, Boudreault A, Durkin J, Gillard JW, Jaquith JB, Morris SJ and Barker PA. cIAP1 and cIAP2 facilitate cancer cell survival by functioning as E3 ligases that promote RIP1 ubiquitination. Molecular cell. 2008; 30:689-700.

5. Zarnegar BJ, Wang Y, Mahoney DJ, Dempsey PW, Cheung HH, He J, Shiba T, Yang X, Yeh WC, Mak TW, Korneluk RG and Cheng G. Noncanonical NF-kappaB activation requires coordinated assembly of a regulatory complex of the adaptors cIAP1, cIAP2, TRAF2 and TRAF3 and the kinase NIK. Nature immunology. 2008; 9:1371-1378.

6. Vallabhapurapu S, Matsuzawa A, Zhang W, Tseng PH, Keats JJ, Wang H, Vignali DA, Bergsagel PL and Karin M. Nonredundant and complementary functions of TRAF2 and TRAF3 in a ubiquitination cascade that activates NIK-dependent alternative NF-kappaB signaling. Nature immunology. 2008; 9:1364-1370.

7. Bai L, Smith DC and Wang S. Small-molecule SMAC mimetics as new cancer therapeutics. Pharmacology \& therapeutics. 2014; 144:82-95.

8. Chai J, Du C, Wu J-W, Kyin S, Wang X and Shi Y. Structural and biochemical basis of apoptotic activation by Smac/DIABLO. Nature. 2000; 406:855-862.

9. Du C, Fang M, Li Y, Li L and Wang X. Smac, a mitochondrial protein that promotes cytochrome c-dependent caspase activation by eliminating IAP inhibition. Cell. 2000; 102:33-42.

10. Verhagen AM, Ekert PG, Pakusch M, Silke J, Connolly LM, Reid GE, Moritz RL, Simpson RJ and Vaux DL. Identification of DIABLO, a mammalian protein that promotes apoptosis by binding to and antagonizing IAP proteins. Cell. 2000; 102:43-53.

11. Yang $\mathrm{QH}$ and Du C. Smac/DIABLO selectively reduces the levels of c-IAP1 and c-IAP2 but not that of XIAP and livin in HeLa cells. The Journal of biological chemistry. 2004; 279:16963-16970.

12. Varfolomeev E, Blankenship JW, Wayson SM, Fedorova AV, Kayagaki N, Garg P, Zobel K, Dynek JN, Elliott LO, Wallweber HJA, Flygare JA, Fairbrother WJ, Deshayes K, Dixit VM and Vucic D. IAP Antagonists Induce Autoubiquitination of c-IAPs, NF- $\kappa \mathrm{B}$ Activation, and TNF $\alpha$-Dependent Apoptosis. Cell. 2007; 131:669-681.

13. Vince JE, Wong WW-L, Khan N, Feltham R, Chau D, Ahmed AU, Benetatos CA, Chunduru SK, Condon SM, McKinlay M, Brink R, Leverkus M, Tergaonkar V, Schneider P, Callus BA, Koentgen F, et al. IAP Antagonists Target cIAP1 to Induce TNF $\alpha$-Dependent Apoptosis. Cell. 2007; 131:682-693.
14. Petersen SL, Wang L, Yalcin-Chin A, Li L, Peyton M, Minna J, Harran P and Wang X. Autocrine TNF $\alpha$ Signaling Renders Human Cancer Cells Susceptible to SmacMimetic-Induced Apoptosis. Cancer cell. 2007; 12:445456.

15. Cheung HH, Mahoney DJ, LaCasse EC and Korneluk RG. Down-regulation of c-FLIP Enhances Death of Cancer Cells by Smac Mimetic Compound. Cancer research. 2009; 69:7729-7738.

16. Tenev T, Bianchi K, Darding M, Broemer M, Langlais C, Wallberg F, Zachariou A, Lopez J, MacFarlane M, Cain K and Meier P. The Ripoptosome, a signaling platform that assembles in response to genotoxic stress and loss of IAPs. Molecular cell. 2011; 43:432-448.

17. Feoktistova M, Geserick P, Kellert B, Dimitrova DP, Langlais C, Hupe M, Cain K, MacFarlane M, Hacker G and Leverkus M. cIAPs block Ripoptosome formation, a RIP1/caspase- 8 containing intracellular cell death complex differentially regulated by cFLIP isoforms. Molecular cell. 2011; 43:449-463.

18. Thibault BG, L.; Broca, C; Barbier, M.; Zanna, C.; Vuagniaux, G.; Delord, J-P.; Couderc, B. (2015). The IAP inhibitor Debio 1143 reverses carboplatin resistance in ovarian cancer cells by inducing both apoptosis and necroptosis. AACR Annual Meeting 2015.

19. Berger R, Jennewein C, Marschall V, Karl S, Cristofanon S, Wagner L, Vellanki SH, Hehlgans S, Rodel F, Debatin KM, Ludolph AC and Fulda S. NF-kappaB is required for Smac mimetic-mediated sensitization of glioblastoma cells for gamma-irradiation-induced apoptosis. Molecular cancer therapeutics. 2011; 10:1867-1875.

20. Liu N, Tao Z, Blanc JM, Zaorsky NG, Sun Y, Vuagniaux G, Dicker AP and Lu B. Debio 1143, an antagonist of multiple inhibitor-of-apoptosis proteins, activates apoptosis and enhances radiosensitization of non-small cell lung cancer cells in vitro. American journal of cancer research. 2014; 4:943-951.

21. Hurwitz HI, Smith DC, Pitot HC, Brill JM, Chugh R, Rouits E, Rubin J, Strickler J, Vuagniaux G, Sorensen JM and Zanna C. Safety, pharmacokinetics, and pharmacodynamic properties of oral DEBIO1143 (AT-406) in patients with advanced cancer: results of a first-in-man study. Cancer chemotherapy and pharmacology. 2015; 75:851-859.

22. Breindel JL, Haskins JW, Cowell EP, Zhao M, Nguyen DX and Stern DF. EGF receptor activates MET through MAPK to enhance non-small cell lung carcinoma invasion and brain metastasis. Cancer research. 2013; 73:5053-5065.

23. Chmielecki J, Foo J, Oxnard GR, Hutchinson K, Ohashi K, Somwar R, Wang L, Amato KR, Arcila M, Sos ML, Socci ND, Viale A, de Stanchina E, Ginsberg MS, Thomas RK, Kris MG, et al. Optimization of Dosing for EGFR-Mutant Non-Small Cell Lung Cancer with Evolutionary Cancer Modeling. Science translational medicine. 2011; 3:90ra5990ra59.

24. Scortegagna M, Lau E, Zhang T, Feng Y, Sereduk C, Yin 
H, De SK, Meeth K, Platt JT, Langdon CG, Halaban R, Pellecchia M, Davies MA, Brown K, Stern DF, Bosenberg $\mathrm{M}$, et al. PDK1 and SGK3 contribute to the growth of BRAF mutant melanomas and are potential therapeutic targets. Cancer research. 2015.

25. Chou T-C. Theoretical Basis, Experimental Design, and Computerized Simulation of Synergism and Antagonism in Drug Combination Studies. Pharmacological Reviews. 2006; 58:621-681.

26. Chou TC. Drug combination studies and their synergy quantification using the Chou-Talalay method. Cancer research. 2010; 70:440-446.

27. Cai Q, Sun H, Peng Y, Lu J, Nikolovska-Coleska Z, McEachern D, Liu L, Qiu S, Yang CY, Miller R, Yi H, Zhang T, Sun D, Kang S, Guo M, Leopold L, et al. A potent and orally active antagonist (SM-406/AT-406) of multiple inhibitor of apoptosis proteins (IAPs) in clinical development for cancer treatment. Journal of medicinal chemistry. 2011; 54:2714-2726.

28. Probst BL, Liu L, Ramesh V, Li L, Sun H, Minna JD and Wang L. Smac mimetics increase cancer cell response to chemotherapeutics in a TNF-alpha-dependent manner. Cell death and differentiation. 2010; 17:1645-1654.

29. Delmore JE, Issa GC, Lemieux ME, Rahl PB, Shi J, Jacobs HM, Kastritis E, Gilpatrick T, Paranal RM, Qi J, Chesi M, Schinzel AC, McKeown MR, Heffernan TP, Vakoc CR, Bergsagel PL, et al. BET bromodomain inhibition as a therapeutic strategy to target c-Myc. Cell. 2011; 146:904917.

30. Mertz JA, Conery AR, Bryant BM, Sandy P, Balasubramanian S, Mele DA, Bergeron L and Sims RJ, 3rd. Targeting MYC dependence in cancer by inhibiting BET bromodomains. Proceedings of the National Academy of Sciences of the United States of America. 2011; 108:16669-16674.

31. Shimamura T, Chen Z, Soucheray M, Carretero J, Kikuchi E, Tchaicha JH, Gao Y, Cheng KA, Cohoon TJ, Qi J, Akbay E, Kimmelman AC, Kung AL, Bradner JE and Wong KK. Efficacy of BET bromodomain inhibition in Kras-mutant non-small cell lung cancer. Clinical cancer research : an official journal of the American Association for Cancer Research. 2013; 19:6183-6192.

32. Lockwood WW, Zejnullahu K, Bradner JE and Varmus H. Sensitivity of human lung adenocarcinoma cell lines to targeted inhibition of BET epigenetic signaling proteins. Proceedings of the National Academy of Sciences of the United States of America. 2012; 109:19408-19413.

33. Matsuda I, Matsuo K, Matsushita Y, Haruna Y, Niwa M and Kataoka T. The C-terminal domain of the long form of cellular FLICE-inhibitory protein (c-FLIPL) inhibits the interaction of the caspase 8 prodomain with the receptorinteracting protein 1 (RIP1) death domain and regulates caspase 8-dependent nuclear factor kappaB (NF-kappaB) activation. The Journal of biological chemistry. 2014; 289:3876-3887.
34. Puyol M, Martin A, Dubus P, Mulero F, Pizcueta P, Khan G, Guerra C, Santamaria D and Barbacid M. A synthetic lethal interaction between K-Ras oncogenes and Cdk4 unveils a therapeutic strategy for non-small cell lung carcinoma. Cancer cell. 2010; 18:63-73.

35. Luo J, Emanuele MJ, Li D, Creighton CJ, Schlabach MR, Westbrook TF, Wong KK and Elledge SJ. A genome-wide RNAi screen identifies multiple synthetic lethal interactions with the Ras oncogene. Cell. 2009; 137:835-848.

36. Kataoka Y, Mukohara T, Tomioka H, Funakoshi Y, Kiyota N, Fujiwara Y, Yashiro M, Hirakawa K, Hirai M and Minami H. Foretinib (GSK1363089), a multi-kinase inhibitor of MET and VEGFRs, inhibits growth of gastric cancer cell lines by blocking inter-receptor tyrosine kinase networks. Investigational new drugs. 2012; 30:1352-1360.

37. Yoshida T, Okamoto I, Okamoto W, Hatashita E, Yamada Y, Kuwata K, Nishio K, Fukuoka M, Janne PA and Nakagawa K. Effects of Src inhibitors on cell growth and epidermal growth factor receptor and MET signaling in gefitinib-resistant non-small cell lung cancer cells with acquired MET amplification. Cancer science. 2010; 101:167-172.

38. Zhang Z, Lee JC, Lin L, Olivas V, Au V, LaFramboise T, Abdel-Rahman M, Wang X, Levine AD, Rho JK, Choi YJ, Choi CM, Kim SW, Jang SJ, Park YS, Kim WS, et al. Activation of the AXL kinase causes resistance to EGFRtargeted therapy in lung cancer. Nature genetics. 2012; 44:852-860.

39. Corcoran RB, Ebi H, Turke AB, Coffee EM, Nishino M, Cogdill AP, Brown RD, Della Pelle P, Dias-Santagata D, Hung KE, Flaherty KT, Piris A, Wargo JA, Settleman J, Mino-Kenudson M and Engelman JA. EGFR-mediated reactivation of MAPK signaling contributes to insensitivity of BRAF mutant colorectal cancers to RAF inhibition with vemurafenib. Cancer discovery. 2012; 2:227-235.

40. Lee S, Challa-Malladi M, Bratton SB and Wright CW. Nuclear factor-kappaB-inducing kinase (NIK) contains an amino-terminal inhibitor of apoptosis (IAP)-binding motif (IBM) that potentiates NIK degradation by cellular IAP1 (c-IAP1). The Journal of biological chemistry. 2014; 289:30680-30689.

41. Tchoghandjian A, Jennewein C, Eckhardt I, Momma S, Figarella-Branger D and Fulda S. Smac mimetic promotes glioblastoma cancer stem-like cell differentiation by activating NF-kappaB. Cell death and differentiation. 2014; 21:735-747.

42. Stadel D, Cristofanon S, Abhari BA, Deshayes K, Zobel K, Vucic D, Debatin KM and Fulda S. Requirement of nuclear factor kappaB for Smac mimetic-mediated sensitization of pancreatic carcinoma cells for gemcitabine-induced apoptosis. Neoplasia. 2011; 13:1162-1170.

43. Maas C, Tromp JM, van Laar J, Thijssen R, Elias JA, Malara A, Krippner-Heidenreich A and Silke J. CLL cells are resistant to smac mimetics because of an inability to form a ripoptosome complex. 2013; 4:e782. 
44. Loder S, Fakler M, Schoeneberger H, Cristofanon $\mathrm{S}$, Leibacher J, Vanlangenakker $\mathrm{N}$, Bertrand MJ, Vandenabeele P, Jeremias I, Debatin KM and Fulda S. RIP1 is required for IAP inhibitor-mediated sensitization of childhood acute leukemia cells to chemotherapy-induced apoptosis. Leukemia. 2012; 26:1020-1029.

45. Ceribelli M, Kelly PN, Shaffer AL, Wright GW, Xiao W, Yang Y, Mathews Griner LA, Guha R, Shinn P, Keller JM, Liu D, Patel PR, Ferrer M, Joshi S, Nerle S, Sandy P, et al. Blockade of oncogenic IkappaB kinase activity in diffuse large B-cell lymphoma by bromodomain and extraterminal domain protein inhibitors. Proceedings of the National Academy of Sciences of the United States of America. 2014; 111:11365-11370.

46. Zhang L, Dittmer MR, Blackwell K, Workman LM, Hostager B and Habelhah H. TRAIL activates JNK and NF-kappaB through RIP1-dependent and -independent pathways. Cellular signalling. 2015; 27:306-314.

47. Kataoka $\mathrm{T}$ and Tschopp J. N-terminal fragment of c-FLIP(L) processed by caspase 8 specifically interacts with TRAF2 and induces activation of the NF-kappaB signaling pathway. Molecular and cellular biology. 2004; 24:26272636.

48. Riley JS, Hutchinson R, McArt DG, Crawford N, Holohan C, Paul I, Van Schaeybroeck S, Salto-Tellez M, Johnston PG, Fennell DA, Gately K, O’Byrne K, Cummins R, Kay E, Hamilton P, Stasik I, et al. Prognostic and therapeutic relevance of FLIP and procaspase- 8 overexpression in nonsmall cell lung cancer. Cell death \& disease. 2013; 4:e951.

49. Kim HS, Mendiratta S, Kim J, Pecot CV, Larsen JE, Zubovych I, Seo BY, Kim J, Eskiocak B, Chung H, McMillan E, Wu S, De Brabander J, Komurov K, Toombs JE, Wei S, et al. Systematic identification of molecular subtype-selective vulnerabilities in non-small-cell lung cancer. Cell. 2013; 155:552-566.

50. Weisberg E, Nonami A, Chen Z, Liu F, Zhang J, Sattler M, Nelson E, Cowens K, Christie AL, Mitsiades C, Wong KK, Liu Q, Gray N and Griffin JD. Identification of Wee1 as a novel therapeutic target for mutant RAS-driven acute leukemia and other malignancies. Leukemia. 2015; 29:2737. 